\title{
HYDROBIOLOGY AND INLAND FISHERIES OF AFRICA
}

$\mathrm{T}$ HE principle of the symposium as a means of taking stock and stimulating new work in science may be said to have a value which is in direct proportion to the isolation of the workers concerned. Thus symposia have special value in the more remote parts of the world where many workers are to-day striving towards common objectives in small institutes or organizations hundreds or even thousands of miles apart. A good example was the symposium on African hydrobiology and inland fisheries which was held during October 14-17, 1952, under the ægis of the Scientific Council for Africa South of the Sahara. It brought together more than forty workers in these subjects from sixteen different territories in Africa, including Belgian, French, Portuguese and British Colonies, the Union of South Africa and Southern Rhodesia. The site was Entebbe in Uganda, appropriate in that it is near the centre of Africa and is lapped on three sides by Africa's largest lake.

The symposium was opened by Sir Andrew Cohen, Governor of Uganda, in an erudite speech in French and English. He mentioned the progress in African scientific co-operation which is being achieved by the Commission for Technical Co-operation in Africa and by the Scientific Council for Africa South of the Sahara, and pointed to the importance of the development of fisheries in solving a major nutritional problem of Africa, particularly in a country like Uganda, which has more than its fair share of lakes and swamps. He referred particularly to the need for scientific background: "It is a commonplace," he said, "so great that it need not be repeated publicly, that one of the main keys to agricultural development lies in the knowledge of soils. In the development of fisheries the water is the soil, and yet we know too little about our waters".

The contributions and discussions inevitably covered a wide range, including comparison of the organizations in the various territories, information services, fish and fisheries of natural waters, fish farming, trout fisheries, hydrobiology in relation to disease, legislation, and the co-ordination of fishery interests with those of agriculture and other subjects in the use of Africa's meagre water supplies. From the Belgian Congo, C. Halain described the successful results of the campaign for establishing numerous fish farms in native areas, and Dr. A. F. de Bont described scientific results achieved in that connexion, these being compared with experience in fish farming contributed by Dr. D. Hey and Dr. S. S. du Plessis from South Africa, J. L. Lemasson and others from the French territories, H. C. Copley and Dr. V. van Someren from Kenya, O. E. Symes from Nigeria, and others. The fish farming industry of Africa is being built mainly on the numerous local species of Tilapia, and this led to discussion on the transportation of fish from one drainage basin or fish region to another. It was generally agreed that, while economic development cannot be held up, it is more important during the next few years to learn more about the local endemic species in their natural waters and under conditions of culture, than to distribute widely those fow species which have already proved themselves useful under domestication.
Sessions devoted to natural waters included some important contributions on production biology from the East African Fishery Research Organization's laboratory at Jinja, which has now been in existence for several years. R. S. A. Beauchamp and G. R. Fish, for example, threw considerable light on the highly complex hydrology of Lake Victoria. Dr. J. Rzoska, from the University College of the Sudan, described hydrobiological researches on the White Nile, particularly the influence of the reservoir contained by the Gebel Aulyia barrage near Khartoum.

An academic note was sounded in discussions of the ecology of tropical swamps introduced by Prof. L. C. Beadle, of Makerere College, and on the biology of speciation in African lakes introduced by Dr. E. B. Worthington. This turned around the debatable problem of sympatric and allopatric speciation, which was argued particularly, by P. H. Greenwood from his studies of Haplochromis flocks in Lake Victoria, Miss R. Lowe on the associations of Tilapia species from Lake Nyasa and elsewhere, and Dr. G. S. Carter, who is spending a year at the Jinja Laboratory on sabbatical leave from Cambridge.

Much new information was brought to light on a variety of African fishes in relation to their environments, particularly those of economic importance and including the introduced species of trout in the highland areas. A feature of the meeting was an account of research on fish-eating birds and on tho ecology and economic status of the crocodile by another visiting worker from Cambridge, Dr. H. B. Cott. His results promoted discussion on the policy which should be adopted by Governments in applying some control to the industry in crocodile skins, which in some waters may threaten the very existence of crocodiles. Whereas views were expressed that the crocodile is an animal which could well be dispensed with in areas of economic fisheries, particularly on account of the destruction which it causes to fishing nets, it was generally admitted that its influence on food chains is yet inadequately known and might sometimes be beneficial. For example, an experience was recounted from Madagascar that the destruction of crocodiles had been associated with an increase in the incidence of rabies: crocodiles no longer eliminated rabid dogs which were drinking.

Prof. J. Millot (of the Muséum d'Histoire Naturelle, Paris, and of Madagascar), who was chairman of the symposium, remarked in his concluding speech that the meeting as a whole had provided the opportunity for a thoroughly useful exchange of experience and views from a very wide region, and the contributions and discussions had achieved a high scientific standard. The fact that the hydrobiology of Africa is achieving a considerable importance and is less isolated than formerly is illustrated by the fact that no less than ten of the participants at this symposium expect to attend the Twelfth International Limnological Congress, to be opened during August at Cambridge. The language problem, which is so apt to impede international meetings, was solved by simultaneous interpretation at the symposium. A full record will appear as an official publication in due course. E. B. WORTHINGTON 